\section{Cardiac sympathetic tone in anaesthetized diabetics}

Kentaro Tsueda MD, Kou Chu Huang MD, Stephen W. Dumont MB FFaRCS, T. Jeffery Wieman MD, Mary H. Thomas MS, Michael F. Heine MD
To assess cardiac sympathetic nervous function in diabetics, the heart rates attained following a pharmacological dose of intravenous atropine, $23 \mu \mathrm{g} \cdot \mathrm{kg}^{-1}$, were studied under $\mathrm{N}_{2} \mathrm{O}$, isoflurane anaesthesia in diabetics $(n=21)$ and nondiabetics $(n$ $=30$ ). Atropine-induced heart rate in diabetics was significantly lower than that in nondiabetics (95 \pm 14 (SD) bpin vs $109 \pm$ $12 \mathrm{bpm}, P<0.001$ ) and were closely related to preoperative orihostatic diastolic blood pressure change $(r=0.60, P<$ $0.01)$. There was some correlation between the atropineinduced heart rate and preoperative $R R$-variation in diabetics $(r=0.50, P<0.05)$. The findings suggest that cardiac sympathetic function may also be impaired in diabetics with orthostatic hypotension.

Afin d'évaluer la fonction du système nerveux sympathique cardiaque chez les diabétiques, la fréquence cardiaque obtenue après une dose pharmacologique intraveineuse d'atropine, 23 $\mu \mathrm{g} \cdot \mathrm{kg}^{-1}$, a été étudiée sous une anesthésie avec le protoxyde d'azoteloxygène/isoflurane chez des diabéliques $(n=21)$ et des non-diabétiques ( $n=30$ ). La fréquence cardiaque induite par l'atropine a été significativement plus basse que celle obtenue chez les non-diabétiques $(95 \pm 14$ (SD) bpm vs $109 \pm 12 \mathrm{bpm}$. $P<0,00 I)$ et ceci était étroitement corrélé avec les changements de la pression artérielle diastolique en période préopératoire et en position osthostatique $(r=0,60, P<0.01)$. Il y avait une certaine corrélation entre la fréquence cardiaque induite par l'atropine et les variations $R R$ en période préopératoire chez les diabétiques $(r=0,50, P<0.05)$. Ceci suggère que la fonction sympathique cardiaque peut aussi être altérée chez les diabétiques présentant de l'hypotension orthostatique.

\section{Key words}

COMPLICATIONS: diabetes;

HEART: autonomic function, atropine.

From the Departments of Anesthesiology and Surgery, University of Louisville, Louisville, Kentucky 40292.

Address correspondence to: Dr. K. Tsueda, Department of Anesthesiology, University of Louisville, Louisville, KY 40292.

Accepted for publication 2/st August, 1990
Sudden deaths without autopsy evidence of myocardial infarction have been described in diabetics with cardiovascular autonomic neuropathy. ' Recently, severe perioperative bradycardia and hypotension ${ }^{2-4}$ as well as cardiac standstill ${ }^{5}$ were reported in diabetics with orthostatic hypotension under well-monitored circumstances where such episodes are not normally expected to occur. The bradycardia was refractory to atropine and ephedrine, suggesting that cardiac sympathetic nerves in addition to the sympathetic innervation to blood vessels and cardiac parasympathetic nerves may have been damaged in these patients. $^{2-4}$

In diabetics the resting heart rate correlates inversely with RR-variation, ${ }^{6}$ and the decrease in RR-variation is related to damage to cardiac parasympathetic nerves. The degree of tachycardia depends on the relative severity of damage to the cardiac parasympathetic and sympathetic nervous systems. As cardiac sympathetic nerve damage progresses, the tachycardia tends to lessen and ultimately results in a fixed heart rate that is equal to the intrinsic rate of the heart. ${ }^{8}$ A recent longitudinal study in diabetics demonstrated an initial increase and a subsequent decline in resting heart rate related to the deterioration of cardiovascular autonomic nervous function. ${ }^{9}$ Current autonomic function tests, however, do not assess cardiac sympathetic neuropathy, ${ }^{10}$ and its natural history has remained unclear.

The peripheral interactions that occur between cardiac parasympathetic and sympathetic postganglionic fibres, i.e., accentuated antagonism and reciprocal excitation, are so complex that observed responses to administered autonomic drugs are difficult to interpret. ${ }^{11.12}$ However, the interactions are abolished either by anticholinergic or $\boldsymbol{\beta}$-adrenergic antagonists, ${ }^{11,12}$ and the pharmacological denervation of the heart results in a moderate tachycardia, which is unresponsive to stimuli. ${ }^{13.14}$ The surgical denervation of the heart, i.e., a transplanted heart, responds similarly. ${ }^{14.15}$ Thus, under basal conditions, heart rate resulting from pharmacological blockade of the cardiac parasympathetic nervous system is expected to reflect unopposed cardiac sympathetic tone. We therefore studied the heart rate attained following a pharmacological dose of atropine in anaesthetized diabetics and its relationship 
to preoperative autonomic function, i.e., RR-variation and orthostatic blood pressure response.

\section{Methods}

Twenty-one diabetics ( 12 men and nine women) and 30 nondiabetics ( 12 men and 18 women) undergoing surgical procedures of the lower extremities were selected for study. Informed consent was obtained from each patient. Patients with frequent arrhythmias, congestive heart failure, angina or a previous history of myocardial infarction, those receiving antiadrenergic drugs, calcium entry blockers or renal dialysis, and those with a history of cerebrovascular accident or carotid artery disease were excluded from the study. None of the patients had a history of alcoholism or drug abuse. Ages ranged from 29 to $62 \mathrm{yr}$ (mean, $49 \pm 10(\mathrm{SD}) \mathrm{yr}$ ) in diabetics and from 18 to $81 \mathrm{yr}(48 \pm 17 \mathrm{yr})$ in nondiabetics.

Sixteen diabetics had one or more of the following symptoms suggestive of autonomic ncuropathy: abnormal sweating of the lower extremities ( 16 patients), gastroparesis (five patients), and orthostatic symptoms (seven patients). Eighteen diabetics had peripheral neuropathy. Seven patients had retinopathy, and six patients had nephropathy. Seventeen patients had ulceration and/or infection of the foot, for which amputation of toes or metatarsals was performed. Eighteen patients were insulin-dependent. Four patients did not have any of the complications of diabetes. The duration of diabetes ranged from 3 to $35 \mathrm{yr}$ (mean, $16 \pm 8 \mathrm{yr}$ ).

The RR-variation, a measure of cardiac parasympathetic nervous function, ${ }^{10}$ was measured in the recumbent position while patients breathed five times per minute for six minutes. An ECG and microprocessor measured each RR-interval to within $1 \mathrm{msec}$, which was recorded continuously by a computer. The RR-variation was measured by a vector analysis technique and expressed as the circular resultant $(\bar{R})$, a unitless number that ranges between 0 and $1 .{ }^{16}$ The times when $R$-waves appeared during a respiratory cycle were plotted on a unit circle, through the centre of which the horizontal ( $x$ ) and the vertical (y) axes were drawn. $\bar{R}$ is the vector mean of all the times during a respiratory cycle and it corresponds to a point in the unit disc. If both vectors of the times on the unit circle are uniformly distributed, $\bar{R}$ will be short. If the points cluster on one region of the circle, $\bar{R}$ will be long. $\bar{R}$ was calculated as follows: $\bar{R}=\left([\Sigma X(\mathrm{Ti}) / \mathrm{n}]^{2}\right.$ $\left.+[\Sigma \mathrm{Y}(\mathrm{Ti}) / \mathrm{n}]^{2}\right)^{\frac{1}{2}}$, where $\Sigma \mathrm{X}(\mathrm{Ti})=\cos (2 \pi \mathrm{Ti} / \lambda)$ and $\mathrm{Y}(\mathrm{Ti})$ $=\sin (2 \pi \mathrm{Ti} / \lambda) . \mathrm{T} 1, \mathrm{~T} 2 .---, \mathrm{Tn}$ were the times at which R-waves were observed in the ECG and $\lambda$ was the period of the breathing cycle. Ectopic beats were carefully edited at the end of the test. The last five minutes of the recording were used for analysis. Blood pressure was measured while the patient was lying in bed and again one minute after standing up. The difference in blood pressure was taken as the measure of orthostatic blood pressure change.

Preanaesthetic medication was not given. Anaesthesia was induced with thiopentone, $5 \mathrm{mg} \cdot \mathrm{kg}^{-1}$, and tracheal intubation was facilitated with succinylcholine. Anaesthesia was maintained with isoflurane and 50 per cent nitrous oxide in oxygen. Muscle relaxation was provided by vecuronium. Respiration was mechanically controlled, and minute volume was adjusted to maintain $\mathrm{PaCO}_{2}$ at about $35 \mathrm{mmHg}$. End-tidal isoflurane concentration was monitored by an Anesthetic Agent Monitor $222^{\circ}$ (Puritan-Bennett Corp., Kansas City, MO). The inspired isoflurane concentration was adjusted towards the end of the operation so that the end-tidal concentration was 0.8 per cent. After completion of the operation and five minutes of nonstimulated steady base-line vital signs, patients received atropine $23 \mu \mathrm{g} \cdot \mathrm{kg}^{-1}\left(1.6 \mathrm{mg} \cdot 70 \mathrm{~kg}^{-1}\right)$ IV. Beat-to-beat heart rate monitored by a NCCOM-3 ${ }^{\oplus}$ (BoMed Medical Manufacturing Ltd., Irvine, CA) was recorded continuously for a minimum of three minutes. Neostigmine was then given to antagonize the effect of the muscle relaxant.

Analysis of covariance was used to test the difference in RR-variation between the groups. Heart rate and blood pressure responses to standing and intraoperative administration of atropine were analyzed by the paired Student's $t$ test, and the differences between groups were analyzed by Student's t test for independent groups. Relationships between variables were assessed by the Pearson correlation coefficient and regression analysis.

\section{Results}

The RR-variation in nondiabetics $\left(\overline{\mathrm{R}} \times 10^{3}, 39.1 \pm 24.2\right.$ [SD]) was inversely related to age $\left(\bar{R} \times 10^{3}=79.3-\right.$ 0.83 [age], $\mathrm{r}=-0.58, P<0.001$ ). RR-variation in diabetics $\left(\bar{R} \times 10^{3}, 12.4 \pm 15.4\right)$ was also related to age but was not related to duration of diabetes. After age adjustment, RR-variation was significantly less in diabetics $(P<0.001)$. In nondiabetics, no significant orthostatic blood pressure change occurred, but in diabetics systolic blood pressure decreased $(P<0.01)$ on standing (Table I). Supine resting heart rate was significantly higher in diabetics.

There were no significant differences between nondiabetics and diabetics in anaesthesia time ( $88 \pm 14$ (SD) vs $82 \pm 16 \mathrm{~min})$, body temperature ( $35.3 \pm 0.6$ vs $36.3 \pm$ $\left.0.7^{\circ} \mathrm{C}\right)$, and $\mathrm{PaCO}_{2}(36.3 \pm 2.0$ vs $35.7 \pm 2.8 \mathrm{mmHg})$. The mean end-tidal isoflurane concentration was slightly lower in diabetics $(0.80 \pm 0.03$ per cent vs $0.78 \pm 0.04$ per cent, $P<0.05$ )

Responses of heart rate and blood pressure to atropine 
TABLE I Orthostatic heart rate and blood pressure responses (mean \pm SD) onc minute after standing in 30 nondiabetics and 2 I diabetics

\begin{tabular}{llrrl}
\hline & & Supine & Upright & $P$ \\
\hline Heart ratc & Nondiabetics & $67 \pm 12$ & $79 \pm 11$ & $<0.001$ \\
(beats min $^{-1}$ ) & Diabetics & $81 \pm 13$ & $94 \pm 11$ & $<0.001$ \\
Systolic blood & Nondiabetics & $131 \pm 18$ & $129 \pm 18$ & NS \\
pressure $(\mathrm{mmHg})$ & Diabetics & $141 \pm 24$ & $128 \pm 27$ & $<0.01$ \\
Diastolic blood & Nondiabetics & $79 \pm 12$ & $79 \pm 12$ & NS \\
pressurc $(\mathrm{mmHg})$ & Diabctics & $83 \pm 16$ & $78 \pm 20$ & NS \\
\hline
\end{tabular}

NS, not significant.

$23 \mu \mathrm{g} \cdot \mathrm{kg}^{-1}$ in anaesthetized patients are summarized in Table 11. Atropine produced a brisk increase in heart rate in both nondiabetics and diabetics but was lower in diabetics than in nondiabetics $(P<0.001)$. This atropineinduced heart rate in diabetics was related to preoperative orthostatic change in diastolic blood pressure $(\mathrm{r}=0.60, P$ $<0.005)$. The individual relationships are shown in the Figure. There was some correlation between the atropineinduced heart rate and RR-variation $(r=0.50, P<0.05)$.

A small increase in diastolic blood pressure occurred following administration of atropine in nondiabetics. The diastolic blood pressure change in diabetics was not significant.

\section{Discussion}

In this study, the unstimulated heart rate attained during standardized anaesthesia following atropine was significantly lower in diabetics than in nondiabetics, suggesting the presence of impaired cardiac sympathetic nervous function in the diabetic patients. This decrease in the atropine-induced heart rate was closely related to preoperative orthostatic diastolic blood pressure changes, but its relationship to RR-variation was weak. Several studies have shown positive but rather weak relationships between cardiac parasympathetic neuropathy and peripheral somatic neuropathy, even after accounting for the con-

TABLE II Heart rate and blood pressure responses (mean \pm SD) to atropinc $23 \mu \mathrm{g} \cdot \mathrm{kg}^{-1}$ in 30 nondiabetics and 21 diabetics during anacsthesia

\begin{tabular}{|c|c|c|c|c|}
\hline & & Anuesthesia & Atropine & $P$ \\
\hline \multirow{2}{*}{$\begin{array}{l}\text { Heart rate } \\
\text { (beats } \cdot \min ^{-1} \text { ) }\end{array}$} & Nondiabetics & $79 \pm 13$ & $109 \pm 12$ & $<0.001$ \\
\hline & Diabctics & $80 \pm 10$ & $95 \pm 14^{*}$ & $<0.001$ \\
\hline \multirow{2}{*}{$\begin{array}{l}\text { Systolic blood } \\
\text { pressure }(\mathrm{mmHg})\end{array}$} & Nondiabetics & $114 \pm 17$ & $119 \pm 19$ & NS \\
\hline & Diabetics & $113 \pm 28$ & $113 \pm 28$ & NS \\
\hline \multirow{2}{*}{$\begin{array}{l}\text { Diastolic blood } \\
\text { pressurc (mmHg) }\end{array}$} & Nondiabetics & $66 \pm 15$ & $73 \pm 16$ & $<0.001$ \\
\hline & Diabctics & $65 \pm 14$ & $67 \pm 16$ & NS \\
\hline
\end{tabular}

${ }^{*} P<0.001$ when compared with nondiabetics; NS, not significant.

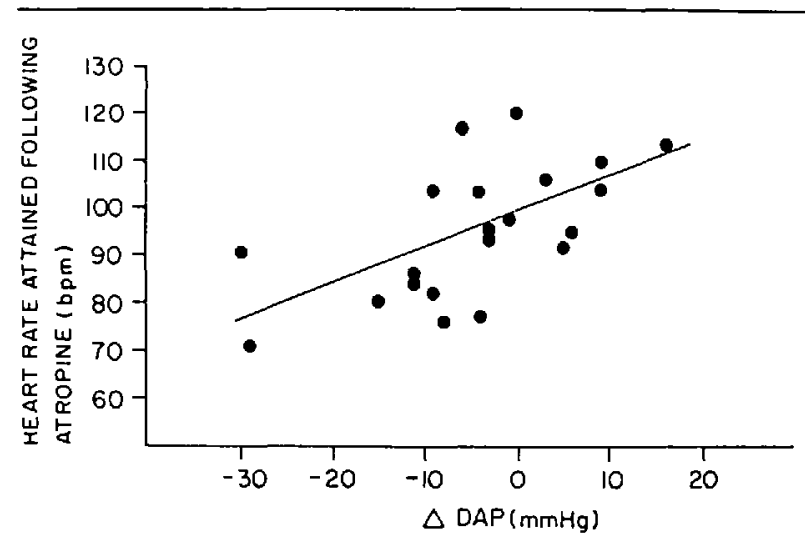

FIGURE The relationship between heart rate attained following atropine $23 \mu \mathrm{g} \cdot \mathrm{kg}^{-1}$ under 0.8 per cent isoflurane and 50 per cent nitrous oxide anaesthesia and preoperative orthostatic diastolic blood pressure change ( $\triangle \mathrm{DBP}$ ). The bold line represents the regression equation $(98.5+[0.73 \times \Delta \mathrm{DBP}], \mathrm{r}=0.60 . P<0.005)$

founding factors that affect RR-variation and nerve conduction, such as age, duration of diabetes and glycaemic control. ${ }^{17-21}$ Recently, Pfeifer et al. demonstrated a relationship between abnormalities in the parasympathetic nervous system to the heart and the iris but no relationship between abnormalities in the sympathetic nervous system to the iris and the parasympathetic nervous system to the iris or the heart. ${ }^{21}$ Thus, although diabetic neuropathies are considered to have similar causes, ${ }^{22.23}$ relationships between abnormalities in different nervous systems are not strong, if any, but abnormalities in the same nervous system in different organs may be related. Our findings are consistent with those reported in these studies and suggest that damage to the sympathetic nervous system to the heart and resistance vessels may develop in parallel in diabetics.

Regulation of the cardiovascular system maintains homeostatic control of arterial blood pressure. Any deviations that result in a decrease in mean arterial blood pressure are countered by sympathoadrenal responses which increase cardiac output and total peripheral resistance. The cardiovascular system, in the absence of sympathetic innervation, is less able to withstand noxious influences. Eleven out of the 13 diabetics with previously described sudden or unexplained cardiorespiratory arrests had orthostatic hypotension. ${ }^{2-5,7}$ In one of these patients, total denervation of the heart was demonstrated pharmacologicaily. ${ }^{7}$ It seems reasonable to assume that sympathetic neuropathy may have played a role in the pathogenesis of the sudden cardiorespiratory collapses. In addition, Page and Watkins have suggested that ventilatory response to hypoxia may be impaired in diabetics with autonomic neuropathy, ${ }^{5}$ since all 12 cardiorespiratory or respiratory arrests they described in eight diabetics were 
associated with circumstances in which hypoxia or respiratory depression was likely to occur.

Forces that tend to perturb cardiovascular homeostasis abound in the perioperative period, when narcotics are frequently used, ventilation to perfusion ratio abnormality may lead to hypoxia, and anaesthetics depress both circulation and respiration. The results of our study suggest that diabetics with orthostatic hypotension may have cardiac sympathetic dysfunction. In these patients, cardiomyopathy may also coexist ${ }^{24}$ and respiratory reflexes may be impaired. ${ }^{5}$ There is a need for cautious observation of diabetics with advanced autonomic neuropathy in the perioperative period.

\section{References}

1 Ewing DJ, Campbell IW, Clarke BF. The natural history of diabetic autonomic neuropathy. Q J Med 1980; NS49: 95- 108

2 Ciccarelli $L L$, Ford CM, Tsueda $K$. Autonomic neuropathy in a diabetic patient with renal failure. Anesthesiology 1986; 64: 283-7.

3 Triantafillou AN, Tsueda K, Berg J, Wieman TJ. Refractory bradycardia after reversal of muscle relaxant in a diabetic with vagal neuropathy. Anesth Analg 1986; 65: $1237-41$.

4 Lucas $L F, T$ sueda $K$. Cardiovascular depression following brachial plexus block in two diabetic patients with renal failure. Anesthesiology (in press).

5 Page $M M C B$, Watkins PJ. Cardiorespiratory arrest and diabetic autonomic neuropathy. Lancet 1978; i: 14-6.

6 Murray A, Ewing DJ, Campbell IW, Neilson JMM, Clarke $B F$. RR-interval variations in young male diabetics. $\mathrm{Br}$ Heart J 1975; 37: 883-5.

7 Lloyd-Mostyn RH, Watkins PJ. Defective innervation of heart in diabetic autonomic neuropathy. Br Med J 1975; 3: $15-7$.

8 Lloyd-Mostyn RH, Watkins PJ. Total cardiac denervation in diabetic autonomic neuropathy. Diabetes 1976; 25 : 748-51

9 Ewing DJ, Campbell IW, Clarke BF. Heart rate changes in diabetcs mellitus. Lancet 1981; 1: 183-6.

10 Ewing DJ, Martyn $C N$, Young RJ, Clarke BF. The value of cardiovascular autonomic function tests: 10 years experience in diabetes. Diabetes Care 1985; 8: 491-8.

11 Levy $M N$. Sympathctic-parasympathetic interactions in the heart. Circ Res 1971; 29: 437-45.

12 Higgins $C B$, Vatner $S F$, Braunwald $E$. Parasympathetic control of the heart. Pharmacol Rev 1978; 25: 119-55.

13 Jose $A D$, Collison $D$. The normal range and determinants of the intrinsic heart rate in man. Cardiovasc Res 1970; 4: 160-7.

14 Leon DF, Shaver JA, Leonard JJ. Reflex heart rate control in man. Am Heart J 1970; 80: 729-39.
15 Shaver JA, Leon DF, Gray S, Leonard JJ, Bahnson $H T$. Hemodynamic observations after cardiac transplantation. N Engl J Med 1969; 281: 822-7.

16 Weinberg $C R$, Pfeifer $M A$. An improved method for measuring heart rate variability: assessment of cardiac autonomic function. Biometrics 1984; 40: 855-61.

17 Bishnu SK, Berenyi MR. Circulatory reflex response in diabetic patients with or without peripheral neuropathy. J Am Geriatr Soc 1971; 19: 159-66.

18 Ewing DJ, Burt AA, Williams IR, Campbell IW, Clarke $B F$. Peripheral motor nerve function in diabetic autonomic ncuropathy. J Neurol Neurosurg Psychiatry 1976; 39: 453-60.

19 Tackmann W, Kaeser HE, Berger W, Rueger AN, Violier $E$. Autonomic disturbances in relation to sensorimotor peripheral neuropathy in diabetes mellitus. J Neurol 1981; 224: 273-81.

20 Young RJ, Ewing DJ, Clarke BF. Nerve function and metabolic control in teenage diabetics. Diabetes 1983; 32: 142-47.

21 Pfeifer MA, Weinberg CR, Cook DL et al. Correlations among autonomic, sensory, and motor neural function tests in untreated non-insulin-dependent diabetic individuals. Diabetes Care 1985; 8: 576-84.

22 Dyck PJ, Lais A, Karnes JL, O'Brien P, Rizza R. Fiber loss is primary and multifocal in sural nerves in diabetic polyneuropathy. Ann Neurol 1986; 19: 425-39.

23 Greene DA. Metabolic abnormalities in diabetic peripheral nerve: relation to impaired function. Metabolism 1983; Suppl. 1, 311: 118-24.

24 Shapiro LM, Leatherdale BA, Mackinnon J, Fletcher $R F$. Left ventricular function in diabetes mellitus: II Relation between clinical features and left ventricular function. Br Heart J 1981; 45: 129-32. 